\title{
PENANAMAN NILAI-NILAI PENDIDIKAN KARAKTER MELALUI SISTEM PEMBELAJARAN PESANTREN DI SMP NEGERI 2 ASEMBAGUS SITUBONDO TAHUN PELAJARAN 2016/2017
}

\author{
Oleh: \\ Minhaji \& Kiki Hermawanti \\ Fakultas Tarbiyah IAI Ibrahimy Situbondo \\ moh_minhaji@yahoo.co.id \& kikihermawati@gmail.com
}

\begin{abstract}
:
This thesis discusses about the Cultivation of Values of Character Education through Pesantren Learning System in SMPN 2 Asembagus. The main questions that will be answered through this research are: (1) The Cultivation of Values of Character Education in SMPN 2 Asembagus ?, (2) The Role of Pesantren Learning System in Cultivating the Values of Character Education in SMPN 2 Asembagus ?. To answer the question then discussed through field study conducted in SMP Negeri 2 Asembagus with descriptive qualitative approach.

The findings of this study indicate that the values of character education are very important to be inculcated through the learning process in school. Education is required to be able to change the students towards the better. The values in character education are expected to be able to print the next generation of strong character through the pesantren learning system. Pesantren learning system in question is through pengajian taysirul kholaq book.

The results showed: (a) the values of character education that have been implanted in SMP Negeri 2 Asembagus is Faith / Religion, Honesty, Self, Discipline, Friendly / Communicative, Curiosity, Hard work, Democracy, Love of Peace, Care for the environment and Maintain cleanliness, Social Care, Spirit of nationality and Love of the homeland. (b) the role of the pesantren learning system in inculcating the values of character education is closely related to have the same orientation of character formation. The value of the characters embedded in the students in SMP Negeri 2 Asembagus is obtained through the study of Taysirul Kholaq as the teaching stage of moral values (Moral Knowing) and the habituation done by the students (Moral Action) so as to give birth to the students with positive character (Moral Feeling).
\end{abstract}

Key Words: Penanaman nilai, Nilai-nilai Pendidikan Karakter dan Sistem Pembelajaran Pesantren. 


\section{A. Pendahuluan}

Karakter bangsa merupakan aspek penting dari kualitas SDM karena kualitas karakter bangsa menentukan kemajuan suatu bangsa. Karakter yang berkualitas perlu dibentuk dan dibina sejak dini, karena merupakan masa kritis bagi pembentukan karakter seseorang.

Thomas Lickona, seorang professor pendidikan dari Cortland University, mengungkapkan bahwa ada sepuluh tanda-tanda zaman yang harus diwaspadai karena jika tanda-tanda ini sudah ada, berarti sebuah bangsa sedang menuju jurang kehancuran. ${ }^{1}$

Tanda-tanda yang dimaksud adalah (1) meningkatnya kekerasan remaja, (2) penggunaan bahasa dan kata-kata yang buruk, (3) pengaruh Peer-Group yang kuat dalam tindak kekerasan, (4) meningkatnya perilaku merusak diri, seperti penggunaan alkohol, narkoba dan seks bebas, (5) semakin kaburnya pedoman moral baik dan buruk, (6) menurunnya etos kerja, (7) semakin rendahnya rasa hormat kepada orang tua dan guru, (8) rendahnya rasa tanggung jawab individu dan warga Negara, (9) membudayanya ketidakjujuran, dan (10) adanya rasa saling curiga dan kebencian di antara sesama. Jika dicermati kesepuluh tanda zaman tersebut sudah ada di Indonesia. ${ }^{2}$

Solusi dari permasalahan tersebut adalah dengan menerapkan pendidikan karakter di setiap jenjang pendidikan. Pendidikan memiliki peran yang sangat penting dalam membentuk pendidikan karakter disekolah. Hal ini sesuai dengan UU No 20 Tahun 2003 Tentang Sistem Pendidikan Nasional pada pasal 3 yang menyebutkan bahwa pendidikan nasional berfungsi mengembangkan kemampuan danlam rangka mencerdaskan kehidupan bangsa.

Pendidikan nasional bertujuan untuk mengembangkan potensi peserta didik agar menjadi manusia yang berimann bertaqwa kepada Tuhan Yang Maha Esa, berakhlak mulia, sehat, berilmu, cakap, kreatif, mandiri, dan menjadi warga Negara yang demokratis serta bertangung jawab. Berdasarkan fungsi dan tujuan pendidikan nasioanl, jelas bahwa pendidikan disetiap jenjang harus diselenggarakan secara sistematis guna mencapai tujuan tersebut. ${ }^{3}$

Dalam dunia pendidikan tidak terlepas dengan kepribadian dan karakter. Dimana kepribadian tersebut merupakan sifat yang dapat diukur

\footnotetext{
1 Masnur Muslich, Pendidikan Karakter Menjawab Tantangan Krisis Multidimensional (Jakarta: PT Bumi Aksara, 2011), hlm. 35.

2 Ibid., hlm. 36.

3 Ibid, hlm. 84.

$274 \mid$ JURNAL LISAN AL-HAL
} 
dan ditunjukkan kepada orang lain, sedangkan karakter mempunyai banyak sekali definisi dari para ahli, menurut poerwadarminta, kata karakter berarti tabiat, watak sifat-sifat kejiwaan, akhlak atau budi pekerti yang membedakan seseorang dengan orang lain. Dalam konteks kajian P3, kami mendefinisikan pendidikan karakter dalam seting sekolah sebagai "pembelajaran yang mengarah pada penguatan dan pengembangan perilaku anak secara utuh yang didasarkan pada suatu nilai tertentu yang dirujuk oleh sekolah."4

Pendidikan karakter merupakan sebuah istilah yang semakin hari semakin mendapatkan pengakuan dari masyarakat Indonesia saat ini. Terlebih dengan dirasakannya berbagai ketimpangan hasil pendidikan dilihat dari perilaku lulusan pendidikan formal saat ini. Tidak sedikit dari kalangan bawah, menengah, hingga orang berpendidikan yang melanggar nilai, norma, agama dan undang-undang yang ada.

Jadi pendidikan karakter adalah sebuah usaha untuk mendidik anak-anak agar dapat mengambil keputusan yang bijak dan mempraktikannya dalam kehidupan sehari-hari, sehingga mereka dapat memberikan kontribusi yang positif kepada lingkungannya.

Menjawab keresahan sebagian masyarakat karena adanya kemerosotan moral bagia anak, SMP Negeri 2 Asembagus Situbondo muncul sebagai alternative solusi dari keresahan sebagian masyarakat. Pendidikan yang ada bertujuan agar siswa-siswinya mempunyai kompetensi yang seimbang, antara ilmu dunia dan akhirat, dengan kata lain SMP Negeri 2 Asembagus Situbondo tidak hanya sekedar mengasah kemampuan berfikir semata, akan tetapi juga kecerdasan emosional dan kecerdasan spiritual.

Ditambah dengan pernyataan Kepala Sekolah SMP Negeri 2 Asembagus Situbondo, yang mengatakan bahwa: "SMP Negeri 2 Asembagus berupaya untuk melaksanakan penanaman nilai-nilai pendidikan karakter dalam setiap proses pembelajarannya, salah satunya termasuk didalam pelajaran tambahan yakni Pembelajaran Pesantren." ${ }^{5}$

Dengan adanya pembelajaran kepesantrenan diharapkan mampu melatih peserta didik untuk menjadikan pribadi yang lebih baik dan sebagai bekal hidup untuk menggapai keselamatan dunia dan akhirat, serta mampu menjadi bangsa yang berkarakter yakni bangsa yang berakhlak dan berbudi pekerti.

${ }^{4}$ Dharma Kusuma, Dkk, Pendidikan Karakter (Kajian Teori Dan Praktik Di Sekolah) (Bandung: PT Remaja Rosdakarya, 2012), hlm. 5.

${ }^{5}$ Suharjono, Wawancara, Asembagus, 11 November 2016. 
Dari uraian diatas dilakukan penelitian untuk mengetahui lebih lanjut tentang bagaimanakah penanaman pendidikan karakter siswa melalui pembelajaran kepesantrenan, dan nilai-nilai apa saja yang muncul dalam pendidikan karakter melalui pembelajaran kepesantrenan. Agar alur penelitian ini lebih sistematis dan orientatif, maka masalah dapat dirumuskan yaitu: Pertama, Bagaimanakah Penanaman Nilai-Nilai Pendidikan Karakter di SMP Negeri 2 Asembagus Situbondo? dan Kedua, Bagaimanakah Peran Sistem Pembelajaran Pesantren Dalam Penanaman Nilai-Nilai Pendidikan Karakter di SMP Negeri 2 Asembagus Situbondo?

\section{B. Metode Penelitian}

Penelitian ini dilaksanakan dengan penelitian kualitatif, metode kualitatif digunakan untuk mendapatkan makna yang mendalam, suatu data yang mengandung makna. Makna adalah data yang sebenarnya, data yang pasti yang merupakan suatu nilai di balik data yang tampak, oleh karena itu tidak menekankan pada generalisasi, tetapi lebih menekankan kepada makna. ${ }^{6}$ Pendekatan ini merupakan suatu proses pengumpulan data secara sistematis dan intensif untuk memperoleh pengetahuan tentang penanaman nilai-nilai pendidikan karakter melalui pembelajaran kepesantrenan di SMP Negeri 2 Asembagus.

Bogdan dan Taylor mendefinisikan bahwa penelitian kualitatif sebagai prosedur penelitian yang menghasilkan data deskriptif berupa kata-kata tertulis atau lisan dari orang-orang dan perilaku yang dapat diamati. ${ }^{7}$

Menurut Kirk dan Miller penelitian kualitatif adalah tradisi tertentu dalam ilmu pengetahuan sosial yang secara fundamental bergantung dari pengamatan pada manusia baik dalam kawasannya maupun dalam peristilahannya.

Pernyataan Denzin dan Lincoln bahwa penelitian kualitatif adalah penelitian yang menggunakan latar alamiah, dengan maksud menafsirkan fenomena yang terjadi dan dilakukan dengan jalan melibatkan berbagai metode yang ada.

Mengemukakan Djam'an Satori dan Aan Komariah penelitian kualitatif adalah penelitian yang menekankan pada quality atau hal yang terpenting dari sifat atau barang atau jasa. Hal terpenting dari suatu barang atau jasa berupa kejadian/ fenomena atau gejala sosial adalah

${ }^{6}$ Ibid., hlm. 15.

7 Lexy J. Moleong, Metodologi Penelitian Kulaitatif ( Bandung: PT Remaja Rosdakarya 2013), hlm. 4.

276 JURNAL LISAN AL-HAL 
makna dibalik kejadian tersebut yang dapat dijadikan pelajaran berharga bagi suatu pengembangan konsep teori. Penelitian kualitatif dapat didesain untuk memberikan sumbangan terhadap teori, praktis, kebijakan, masalah-masalah sosial dan tindakan. ${ }^{8}$

Dari kajian tentang definisi-definisi tersebut dapatlah disintesiskan bahwa penelitian kualitatif adalah penelitian yang bermaksud untuk memahami fenomena tentang apa yang dialami oleh subjek penelitian misalnya perilaku, persepsi, motivasi, tindakan, dan lainnya secara historistik, dan dengan cara deskripsi dalam bentuk kata-kata dan bahasa, pada suatu konteks khusus yang alamiah dan dengan memanfaatkan berbagai metode alamiah. ${ }^{9}$

Penelitian ini ditunjukkan untuk memahami fenomena-fenomena sosial dari sudut atau perspektif partisipan. Partisipan adalah orang-orang yang akan diajak wawancara, diobservasi, dimintai member data, pendapat, pemikiran dan persepsinya.

Phenomenalogical research is a strategy of inquiry in which the researcher identifies the essence of human experiences about a phenomenon as described by participant understanding the lived experiences marks phenomenology as a philosophy as well as a method, and the prosedur involves studying a small number of subjects through extensive and prolonged engagement to develop patterns and relantionship of meaning. ${ }^{10}$

Pada dasarnya penelitian ini meneliti tentang fenomena pengalaman sosial manusia yang dilihat dari sudut pandang paartisispan dengan cara mendeskripsikannya.

\section{Hasil dan Pembahasan}

\section{Penanaman Nilai-Nilai Pendidikan Karakter}

\section{Di SMP Negeri 2 Asembagus Situbondo}

Pendidikan karakter yang dilakukan di instansi pendidikan dapat dilakukan dengan selalu memberikan arahan mengenai konsep baik dan buruk sesuai tahapan usia anak. Karakter adalah mustika hidup yang membedakan manusia dengan hewan atau binatang. Manusia tanpa karakter adalah manusia yang sudah "membinatang". Orang-orang yang berkarakter baik dan kuat secara individual maupun sosial ialah mereka

8 Djam'an Satori, Aan Komariah, Metodologi Penelitian Kualitatif (Bandung: Alfabeta, 2010), hlm. 22.

9 Lexy J. Moleong, Metodologi Penelitian Kulaitatif (Bandung: PT Remaja Rosdakarya, 2014), hlm. 6.

10 John. W. Creswell, Research Design: (Qualitive, And Mixed Methods Approaches) (California: Sage Publication, 2009), hlm. 13. 
yang memiliki akhlak, moral, dan budi pekerti yang baik. Mengingat begitu urgennya karakter, maka insititusi pendidikan memiliki tanggung jawab untuk menanamkannya melalui proses pembelajaran. ${ }^{11}$

Pendidikan karakter atau budi pekerti plus adalah suatu yang urgent untuk dilakukan, kalau kita peduli untuk meningkatkan mutu lulusan SD, SMP, dan SMA maka tanpa pendidikan karakter adalah usaha yang sia-sia. Ingatlah kata-kata bijak dari pemikir besar dunia berikut. Martin Luther King pernah berkata dalam Masnur Muslich: "intelligence plus character that is the goal of true education" (kecerdasan plus karakter itu adalah tujuan akhir dari pendidikan sebenarnya). ${ }^{12}$

Nilai-nilai dalam pendidikan karakter di Indonesia diidentifikasikan berasal dari empat sumber. Pertama, agama. Oleh karena itu, kehidupan individu, masyarakat, dan bangsa selalu didasari pada ajaran agama dan kepercayaannya. Kedua, pancasila. Negara Kesatuan Republik Indonesia ditegakkan atas prinsip-prinsip kehidupan kebangsaan dan kenegaraan yang disebut pancasila. Pancasila terdapat pada pembukaan UUD 1945 yang dijabarkan lebih lanjut kedalam pasal-pasal yang terdapat dalam UUD 1945, artinya nilai-nilai yang terkandung dalam pancasila mengatur kehidupan politik, hokum, ekonomi, kemasyarakatan, budaya dan seni. Ketiga, budaya. Sebagai suatu kebenaran bahwa tidak ada manusia yang hidup bermasyarakat yang tidak disadari nilai-nilai budaya yang diakui masyarakat tersebut. Keempat, tujuan Pendidikan Nasional. Undangundang Republik Indonesia Nomor 20 Tahun 2003 tentang Sistem Pendidikan Nasional merumuskan fungsi dan tujuan pendidikan nasional yang harus digunakan dalam mengembangkan upaya pendidikan Indonesia.

Pasal 3 UU Sisdiknas menyebutkan, "Pendidikan nasional berfungsi mengembangkan dan membentuk watak serta peradaban bangsa yang bermartabat dalam rangka mencerdaskan kehidupan bangsa, bertujuan untuk mengembangkan potensi peserta didik agar menjadi manusia yang beriman dan bertaqwa kepada Tuhan Yang Maha Esa, berakhlak mulia, sehat, berilmu, cakap, kreatif, mandiri, dan menjadi warga Negara yang demokratis dan bertanggung jawab". Berdasarkan keempat sumber nilai tersebut, teridentifikasi 18 nilai untuk pendidikan karakter, yakni 1 . Religius, 2. Jujur, 3. Toleransi, 4. Disiplin, 5. Kerja Keras, 6. Kreatif, 7.

11 Zubaedi, Desain Pendidikan Karakter Konsepsi Dan Aplikasinya Dalam Lembaga Pendidikan (Jakarta: Kencana, 2011), hlm. 1.

12Masnur Muslich, Pendidikan Karakter Menjawab Tantangan Krisis Multidimensional (Jakarta: Pt Bumi Aksara, 2011), hlm. 31.

$278 \mid$ JURNAL LISAN AL-HAL 
Mandiri, 8. Demokratis, 9. Rasa Ingin Tahu, 10. Semangat Kebangsaan, 11. Cinta Tanah Air, 12. Menghargai Prestasi, 13. Bersahabat/ Komunikatif, 14. Cinta Damai, 15. Gemar Membaca, 16. Peduli Lingkungan, 17. Peduli Sosial, 18. Tanggung Jawab. ${ }^{13}$

Sekolah dan guru dapat menambah ataupun mengurangi nilai-nilai tersebut sesuai kebutuhan yang diperlukan dilingkungan sekolah. Adanya hal tersebut sekolah menerapkan sistem pembelajaran pesantren dalam menanamkan nilai-nilai pendidikan karakter, melalui pemahaman tentang materi akhlak melalui pengajian kitab taysirul kholla' dan pembiasaanpembiasan baik yang dilakukan oleh guru di SMP Negeri 2 Asembagus. Diharapkan menjadi solusi terbaik, dalam mengurangi krisis moral dan akhlak yang terjadi. Nilai-nilai pendidikan karakter yang ditemukan di SMP Negeri 2 Asembagus Situbondo, adalah:

Pertama, Keimanan/ Religius. Keimanan merupakan nilai karakter dalam hubungannya dengan Tuhan Yang Maha Esa yang bersifat religius. Dengan kata lain pikiran, perkataan dan tindakan seseorang diupayakan selalu berdasarkan nilai-nilai ketuhanan dan ajaran agama.

Pada praktiknya sebelum Siswa SMP Negeri 2 Asembagus terbiasa melakukan kegiatan keagamaan/ dzhikir yang diisi dengan membaca AlQur'an, membaca Asmaul Husna dan Sholawat Nariyah, dan dilanjutkan dengan sholat dhuha berjama'ah sebelum jam pelajaran dimulai, mengucap salam ketika bertemu guru, bersalaman sebelum pelajaran dimulai, memulai dan mengakhiri pembelajaran dengan berdo'a dan SMP Negeri 2 Asembagus membiasakan untuk melakukan sholat dhuhur berjama'ah di musholla sekolah, berqurban di hari raya idul adha, memberikan zakat fitrah dan mengadakan jum'at sodaqoh.

Kedua, Kejujuran. Agama memerintahkan kejujuran dan melarang kebohongan. Orang yang mempunyai harga diri tidak akan merendahkan dirinya dengan berbohong. Allah berfirman dalam Q.S Al-Ahzab ayat 70 yang artinya:

"Hai orang-orang yang beriman, bertaqwalah kamu sekalian kepada Allah dan katakanlah perkataan yang benar, yakni perkataan yang tidak menyalahi."14

Pada dasarnya kejujuran itu harus dipraktikan dalam kehidupan sehari-hari. Dilihat dari praktiknya, dengan pemahaman tentang pentingnya kejujuran, siswa SMP Negeri 2 Asembagus berkata jujur ketika

13 Zubaedi, Desain Pendidikan Karakter Konsepsi Dan Aplikasinya Dalam Lembaga Pendidikan (Jakarta: Kencana, 2011), hlm. 75-76.

${ }^{14}$ Al-Qur'an Terjemahan, (Al-Ahzab): 70.

\begin{tabular}{l|l} 
JURNAL LISAN AL-HAL & 279
\end{tabular} 
ditanya alasan kenapa tidak mengikuti sholat dhuha berjama'ah, tidak menyontek saat mengerjakan UAS semester genap.

Ketiga, Mandiri. Sikap dan perilaku yang mencerminkan tidak mudah bergantung pada orang lain. Pada praktiknya siswa mengerjakan sendiri tugas individu yang diberikan kepadanya yang merupakan suatu kewajiban sebagai siswa.

Keempat, Disiplin. Tindakan yang menunjukkan perilaku tertib dan patuh pada berbagai ketentuan dan peraturan. Kedisiplinan diterapkan dengan baik di SMP Negeri 2 Asembagus, terutama kedisiplinan dalam hal waktu, seperti awal datang kesekolah dan segala kegiatan yang dilakukan oleh siswa tepat waktu tanpa arahan dari guru, misal kegiatan keagamaan/ dzikir yang berlanjut dengan sholat dhuha berjama'ah dan mengumandangkan adzan saat sholat dhuhur serta sholat sholat dhuhur berjama'ah dan pengajian kitab.

Kelima, Bersahabat atau Komunikatif. Allah SWT berfirman yang artinya "Berpeganglah kamu sekalian dengan tali Allah dan janganlah berpecah-belah", kita sebagai umat muslim diharuskan menjaga tali persaudaraan (persahabatan). Pada praktiknya siswa SMP Negeri 2 Asembagus tidak terlihat ada siswa yang duduk sendirian atau merenung sendirian, budaya menyapa dan ramah meskipun belum kenal, hal ini dirasakan peneliti pada saat pertama kali datang untuk melaksanakan Praktik Pengalaman Lapangan dan Penellitian, karena mereka dibekali dengan pemahaman agar selalu menjaga tali persaudaraan dan tidak memutusnya, hal tersebut merupakan isi dari kitab taysirul kholaq yang diajarkan di SMP Negeri 2 Asembagus dengan tidak memilih-milih dalam berteman.

Keenam, Rasa ingin tahu. Sikap dan tindakan yang selalu berupaya untuk mengetahui lebih mendalam dan meluar dari sesuatu yang dipelajari, dilihat dan didengar. Rasa ingin tahu pada setiap siswa terlihat pada saat dimana guru memberikan kesempatan untuk bertanya pada materi tauhid yang diberikan, peran aktif siswa sangat terlihat dengan sebagian siswa yang bertanya dengan mengesampingkan ego dan rasa malu terhadap teman-temannya.

Ketujuh, Kerja keras. Kerja keras merupakan perilaku bersungguhsungguh dalam kegiatan atau tugas yang dilakukan, terlihat saat siswa bersungguh-sungguh dalam mengatasi hambatan belajar dan menyelesaikan tugas dengan sebaik-baiknya. Praktiknya siswa dengan penuh tanggung jawab dan sadar akan kewajibannya sebagai siswa menyelesaikan tugas yang diberikandari SMP Negeri 2 Asembagus, serta 
mengikuti kegiatan sekolah, kegiatan pesantren dan pengajian kitab dengan bersungguh-sungguh.

Kedelapan, Demokratis. Cara berfikir, bersikap dan bertindak yang menilai sama hak dan kewajiban dirinya dengan orang lain. Praktiknya di SMP Negeri 2 Asembagus adanya Kampanye Osis yang dilakukan setiap pergantian Ketua dan Wakil Osis yang baru. Hal tersebut juga termasuk kedalam Prinsip dari nilai-nilai demokratis yang sudah ditanamkan di sekolah.

Kesembilan, Cinta damai. Agama islam sangat mencintai perdamaian, seperti halnya cinta kasih bagi seluruh alam. Dengan belajar pendidikan agama islam dan pendidikan pesantren di SMP Negeri 2 Asembagus sejenak siswa diingatkan kembali akan hakikatnya hidup di dunia semata-mata hanya untuk menyembah dan beribadah kepada Allah. Mengingatkan untuk selalu berbuat Amar Ma'ruf Nahi Munkar dan agar saling menghargai setiap orang yang ada disekitar kita, baik beda agama, bahasa, budaya dan lain-lainnya. Di SMP Negeri 2 Asembagus dalam praktiknya, siswa menghindari tawuran dan bertengkar, baik dalam lingkup sekolah atau tidak.

Kesepuluh, Gemar membaca. Gemar membaca terlihat saat guru meminta siswa membekali diri dengan belajar terlebih dahulu, seperti mencari informasi dan refrensi lain di perpustakaan sekolah sebagai tugas sekolah dan mencari arti dari bahasa arab yang belum diketahui dalam pembelajaran bahasa arab.

Kesebelas, Peduli lingkungan. Sikap dan tindakan yang selalu berupaya menjaga dan melestarikan lingkungan sekitar sekolah, terlihat saat siswa SMP Negeri 2 Asembagus merawat tanaman yang ada disekolah dengan menyiramnya setiap pagi. Menjaga kebersihan kelas, halaman sekolah, pakaian dan badan juga terlihat saat siswa sadar tentang pentingnya membuang sampah sembarangan dan berpakain rapi dan bersih saat ke sekolah.

Keduabelas, Peduli social. Allah SWT menciptakan manusia sebagai makhluk sosial yang saling membutuhkan satu sama lain, disamping diperintah untuk beribadah kepada-Nya, manusia juga diperintahkan untuk menjaga hubungan hak sesamanya. Di SMP Negeri 2 Asembagus menunjukkan sikap atau tindakan yang selalu ingin member bantuan kepada masyarakat yang membutuhkan, dengan membagikan zakat kepada warga sekitar sekolah yang dianggap tidak mampu, menjenguk guru atau siswa yang benar-benar sakit, melakukan qurban yang mana hal tersebut merupakan hak tetangga seperti yang telah dijelaskan dalam kitab Taysirul Kholaq. 
Ketigabelas, Semangat kebangsaan dan Cinta tanah air. Semangat kebangsaan dan cinta tanah air tidak dapat terlihat dalam proses pembelajaran pendidikan pesantren, akan tetapi dengan sekolah rutin melakukan upacara bendera merah putih di hari senin, disamping itu melatih siswa untuk latihan terlebih dahulu di hari sabtunya, bagi kelas yang mempunyai bagian menjadi pelaksana upacara dan aktif dalam mengikuti kegiatan agustusan/ kemerdekaan, merupakan cerminan bahwa sekolah cinta terhadap tanah air dan mempunyai semangat kebangsaan yang tinggi.

Berikut adalah bagan untuk menyajikan data agar mempermudah penafsiran mengenai nilai-nilai pendidikan karakter yang ada di SMP Negeri 2 Asembagus melalui sistem pembelajaran pesantren, dalam bagan/ gambar 4.1:

282 JURNAL LISAN AL-HAL 


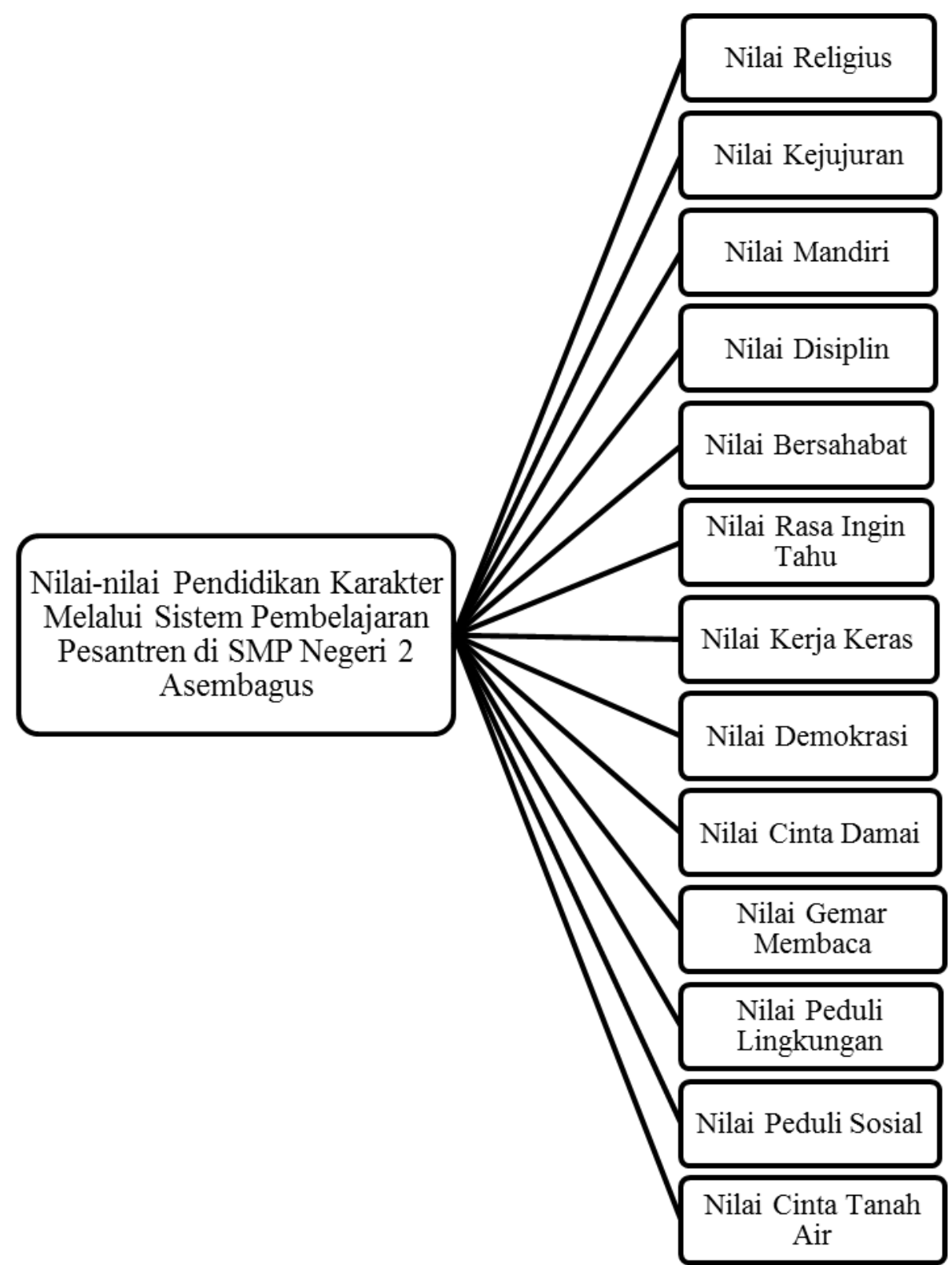

2. Peran Sistem Pembelajaran Pesantren Dalam Penanaman NilaiNilai Pendidikan Karakter Di SMP Negeri 2 Asembagus Situbondo

Dalam konteks pendidikan formal disekolah, bisa jadi salah satu penyebabnya karena pendidikan di Indonesia hanya menitikberatkan 
kepada pengembangan intelektual atau kognitif, sedangkan aspek soft skils cenderung diabaikan. ${ }^{15}$

Terpuruknya bangsa dan Negara Indonesia tidak hanya disebabkan oleh krisis ekonomi melainkan juga oleh krisis akhlak. Oleh karena itu, perekonomian bangsa menjadi ambruk, korupsi dan perbuatan yang merusak bangsa merajalela. Perbuatan yang merugikan diantaranya, perkelahian, pemerkosaan, minum minuman keras dan pencurian. Keadaan seperti itu yang disebut krisis moral dan akhlak, karena kesalahan dunia pendidikan yang kurang menyiapkan generasi muda bangsanya.

Peran Sistem Pembelajaran Pesantren dalam Penanaman Nilai Pendidikan Karakter dirasa sangat efektif dalam menghadapi krisis moral dan akhlak yang terjadi di zaman sekarang khususnya dalam jenjang usia remaja. Dalam pendidikan karakter siswa disekolah keteladanan merupakan metode yang efektif karena siswa pada usia dasar dan menengah pada umumnya cenderung meneladani guru. Secara psikologis siswa memang senang meniru, tidak saja yang baik, bahkan terkadang jelekpun mereka tiru. Keteladanan memang menjadi hal klasik bagi berhasilnya sebuah tujuan pendidikan karakter.

Pembiasaan yang dilakukan secara berulang-ulang akan menjadi suatu kebiasaan, juga dilakukan di SMP negeri 2 Asembagus melalui pembiasaan dalam memupuk sikap karakter siswa, dengan pembiasaan seperti itu, bagi siswa dan guru yang akan membiasakan mereka melakukan perilaku terpuji (akhlak mulia). Oleh karena itu, pembiasaan yang dilakukan sangat efektif dalam rangka pembinaan karakter dan kepribadian siswa.

Pendidikan karakter pada dasarnya melekat pada semua mata pelajaran, karena pada setiap mata pelajaran memiliki nilai-nilai karakter yang harus dilalui dan dicapai oleh siswa. Sehubungan dengan hal tersebut, dengan diterapkannya Sistem Pendidikan Pesantren khususnya pada materi akhlak, yang memiliki hubungan yang erat dalam menanamkan nilai-nilai pendidikan karakter, terbukti memilki orientasi yang sama, yakni pembentukan karakter.

Pembelajaran akhlak di SMP Negeri 2 Asembagus diterapkan melalui pengajian kitab dengan menggunakan kitab Taysirul Kholaq yang dapat memberikan kemudahan bagi masyarakat luas dalam memahami dan mengamalkan konsep akhlak al-karimah. Ilmu akhlaq adalah pengertian

15 Zubaedi, Desain Pendidikan Karakter Konsepsi Dan Aplikasinya Dalam Lembaga Pendidikan (Jakarta: Kencana, 2011), hlm. 3.

$284 \mid$ JURNAL LISAN AL-HAL 
dari aturan-aturan memperbaiki hati dan semua anggota, subjeknya membicarakan budi pekerti dari segi berhias dengan kebaikan dan mengosongkan keburukan-keburukan. Pengajian kitab yan dilakukan di musholla, merupakan unsur dalam pondok pesantren.

Nilai-nilai budi pekerti dalam kitab Taysirul Kholaq juga termasuk kedalam nilai-nilai dalam pendidikan karakter, meskipun sebagian nilai dalam pendidikan karakter yang tidak terlihat dalam proses pembelajaran pendidikan pesantren, melainkan menjadi keseharusan setiap jenjang pendidikan di Indonesia. Jadi, menanamkan nilai-nilai pendidikan karakter juga bisa diterapkan dengan pengajian kitab Taysirul kholaq.

Dengan melihat materi yang ada dalam kitab Taysirul Kholaq, diantaranya berisi tentang ketaqwaan, adab guru, adab murid, hak-hak kedua orang tua, hak saudara, hak tetangga, adab pergaulan, persahabatan, persaudaraan, adab makan dan minum, kebersihan, jujur dan dusta, amanah, memelihara diri, bijaksana, menghindari sifat zhalim, adu domba, gossip dan takabbur/ sombong dan lain sebagainya.

Pelajaran ketaqwaan sudah jelas diberikan untuk memupuk nilai religius dalam siswa, dengan mengerjakan apa yang menjadi perintah Allah SWT, dibuktikan dengan pembiasan-pembiasan yang dilakukan oleh siswa tanpa adanya arahan dari guru, seperti kegiatan dzikir, sholat dhuha dan dhuhur berjama'ah, membaca do'a sebelum dan sesudah kegiatan, bersalaman kepada guru, mengadakan jum'at sodaqoh, berqurban dan berzakata fitrah, dan materi lainnya yang berkaitan dengan nilai-nilai pendidikan karakter. Pembentukan karakter baik terlihat jelas dari materi yang ada didalam kitab Taysirul Kholaq, sebagai dasar pembentukan karakter baik bagi siswa.

Pengajian kitab dengan menggunakan metode bandongan merupakan system pendidikan kolektif yang dilakukan oleh sekelompok santri dengan seorang kyai sebagai pengajarnya. ${ }^{16}$ Berbeda dengan SMP Negeri 2 Asembagus, sososk kyai yang diganti oleh guru pengampu pembelajaran pesantren sebagai pengajarnya, dan sekelompok siswa SMP Negeri 2 Asembagus. Metode bandongan dipilih karena pendidik ingin memfokuskan kepada pembentukan akhlak dan moral siswa, menggunakan kitab Taysirul Kholaq sebagai dasar ajaran dalam menanamkan nilai akhlakul karimah begitu pula nilai yang terkandung dalam pendidikan karakter, dengan sistem pengajian kitab guru dapat memfokuskan dalam pembentukan karakter anak, tanpa memikirkan materi yang harus dicapai, seperti layaknya Pembelajaran PAI.

16 Zamahsyari Dhofier, Tradisi Pesantren (Jakarta: Lp3es), hlm. 45.

$$
\text { JURNAL LISAN AL-HAL } \mid 285
$$


Tujuan Pondok Pesantren pada umumnya, pertama, mendidik santri menjadi anggota masyarakat yang muslim dan bertaqwa kepada Allah SWT, berakhlak mulia, memiliki kecerdasan, ketrampilan dan sehat lahir batin sebagai warga Negara yang berpancasila. Kedua, Mendidik siswa/santri agar menjadi tenaga-tenaga yang cakap dalam berbagai sector pembangunan, khususnya pembangunan mental spiritual. Ketiga, mendidik siswa/santri untuk memperoleh kepribadian dan mempertebal semangat kebangsaan agar dapat menumbuhkan manusia-manusia pembangunan yang dapat membangun dirinya dan bertanggung jawab kepada pembangunan bangsa dan negara. Keempat, siswa/santri agar menjadi tenaga-tenaga yang cakap dalam berbagai sector pembangunan, khususnya pembangunan mental spiritual, dan lain sebagainya. ${ }^{17}$

Senada dengan itu, tujuan pendidikan karakter melalui system pembelajaran pesantren di SMP Negeri 2 Asembagus diharapkan juga bertujuan untuk mendidik siswa menjadi muslim yang bertaqwa kepada Allah SWT, mendidik siswa agar menjadi tenaga yang cakap dalam berbagai sector pembangunan, khususnya pembangunan mental spiritual, mengembangkan kebiasaan dan perilaku siswa yang terpuji dan sejalan dengan nilai-nilai bangsa yang religius, mengembangkan lingkungan hidup yang aman, jujur, persahabatan, memilki rasa tanggung jawab, mandiri, gotong royong, peduli sesama, rasa kebangsaan yang tinggi, dan mendidik siswa menjadi kader ulama dan muballigh yang mengamalkan ajaran islam dengan baik. Dengan begitu visi dan misi sekolah dapat terealisir dengan baik.

Keterkaitan antara pengajian kitab Taysirul Kholaq dengan penanaman nilai-nilai pendidikan karakter terbukti dengan adanya nilainilai pendidikan karakter yang telah tertanam dalam diri siswa SMP Negeri 2 Asembagus yang telah menjadi kebiasaan bagi mereka sebagai siswa SMP Negeri 2 Asembagus dapat dirinci sebagai berikut:

a. Nilai Keimanan meliputi kegiatan: 1) Dzikir (Membaca Al-Qur'an, Asmaul Husna dan Sholawat Nariyah); 2) Sholat Dhuha Berjama'ah; 3) Bersalaman kepada guru; 4) Membaca do'a sebelum dan sesudah kegiatan pembelajaran; 5) Sholat Dhuhur Berjama'ah; 6) Jum'at sodaqoh; 7) Berqurban pada hari raya Idul Adha; dan 8) Memberikan Zakat Fitrah di Bulan Suci Ramadhan kepada tetangga dekat sekolah yang layak mendapatkan.

b. Nilai kejujuran meliputi: 1). Membiasakan sikap jujur, seperti tidak menyontek saat Mengerjakan soal ulangan, baik, ulangan harian, UTS

17 Ibid., hlm. 28.

$286 \mid$ JURNAL LISAN AL-HAL 
dan UAS; dan 2) Membiasakan berkata jujur dalam segala urusan, seperti jujur saat ketahuan menyontek saat ulangan, tidak hadir mengikuti kegiatan sekolah dan bolos ke sekolah.

c. Nilai Mandiri berupa kegiatan mengerjakan tugas secara mandiri.

d. Nilai Disiplin meliputi kegiatan: 1) Awal datang kesekolah; 2) Tepat waktu melaksanakan Kegiatan Dzikir (Tanpa arahan guru); 3) Disiplin megikuti Sholat Dhuha Berjama'ah; dan 4) Disiplin megikuti Sholat Dhuhur Berjama'ah.

e. Nilai Bersahabat atau Komunikatif dengan kegitan berupa: 1) Tolongmenolong antar teman dalam kebaikan dan 2) Menjaga persahabatan tanpa memilih-milih teman

f. Nilai Rasa Ingin Tahu berupa kegiatan Aktif dalam setiap pembelajaran, khususnya Pembelajaran Kepesantrenan, dengan mengesampingkan ego dan rasa malu

g. Nilai Kerja keras diwujudkan dengan kegiatan: 1) Bersungguhsungguh mengikuti Kegiatan Sekolah, Kegiatan Pesantren dan Pengajian Kitab; 2) Mengerjakan tugas yang diberikan dengan bersungguh-sungguh.

h. Nilai Demokrasi diwujdukan dengan kegiatan Kampanye Osis (yang dilakukan ketika pemilihan calon Ketua dan Wakil Osis baru yang berorasi didepan siswa lain di halaman sekolah)

i. Nilai Cinta damai dengan kegiatan 1) Menghindari tawuran antar teman/ sekolah dan 2) Menghindari bertengkar antar teman

j. Nilai Gemar Membaca diwujudkan dengan kegiatan: 1) Mencari refrensi/ informasi lain di perpustakaan sekolah, seperti: Mencari arti bahasa arab dikamus yang disediakan perpustakaan; dan 2) Meminta siswa membekali diri dengan belajar sebelum pelajaran dimulai.

k. Nilai Cinta Lingkungan/ Peduli Lingkungan meliputi: 1) Menjaga Kebersihan kelas dan halaman sekolah; 2) Menyiram tanaman yang ada di lingkungan sekolah; dan 3) Membiasakan Menjaga kebersihan badan, tempat dan pakaian

l. Nilai Peduli Sosial dengan kegiatan: 1) Berqurban pada Hari Raya Idul Adha; 2) Mengeluarkan Zakat Fitrah pada Hari Raya Idul Fitri; 3) Menjenguk siswa dan guru yang sedang sakit; dan 4) Mengadakan Jum'at Sodaqoh

m. Nilai Semangat Kebangsaan dan Cinta Tanah Air dengan kegiatan: 1) Upacara Bendera Merah Putih (Hari Senin); 2) Berlatih upacara di hari sabtu terlebih dahulu sebelum Upacara Bendera dilaksanakan. (petugas upacara dilakukan setiap kelas secara bergantian dan latihan 
dibimbing oleh wali kelas masing-masing); dan 3) Aktif mengikuti kegiatan Agustusan.

Menurut William Kilpatrick dalam Masnur Muslich mengatakan, salah satu penyebab ketidakmampuan seorang anak berperilaku baik, walaupun secara kognitif ia mengetahuinya (moral knowing) karena ia tidak terlatih untuk melakukan kebajikan, untuk itu orang tua dan guru tidak cukup memberikan pengetahuan tentang kebaikan, tetapi harus membimbing anak pada tahap implementasi pada kehidupan seharihari. ${ }^{18}$

Untuk itu, peran Tri pusat pendidikan dalam pemebentukan karakter agar pengetahuan anak tentang moral menjadi suatu perbuatan atau kebiasaan dalam kehidupan sehari-hari. Menurut Ki Hajar Dewantara dalam Sofan Amri Tri Pusat Pendidikan meliputi: lingkungan keluarga, sekolah dan masyarakat. ${ }^{19}$ Sesuai dengan hasil wawancara dengan Kepala Sekolah SMP Negeri 2 Asembagus yang menyatakan bahwa peran Tri Pusat menjadi hal penting dalam pembentukan karakter anak melalui nilai-nilai karakter yang sudah ditanamkan di sekolah dan di rumah.

Dalam pendidikan karakter menekankan pentingnya tiga komponen karakter yang baik, yaitu moral knowing (pengetahuan tentang moral), moral feeling (perasaan tentang moral), moral action (perbuatan moral). Hal tersebut diperlukan agar anak mampu memahami, merasakan dan mengerjakan sekaligus nilai-nilai kebajikan. ${ }^{20}$

Memberikan siswa pengetahuan tentang nilai-nilai moral (moral knowing) melalui Sistem Pembelajaran Pesantren dalam pengajian kitab Taysirul Kholaq di SMP Negeri 2 Asembagus menjadi hal yang mendasar agar siswa mengetahui tentang nilai-nilai moral dalam membentuk akhlakul karimah.

Moral feeling adalah Aspek lain yang harus ditanamkan kepada siswa yang merupakan sumber energy dari diri manusia untuk bertindak sesuai dengan prinsip-prinsip moral, dari pengajian kitab Taysirul Kholaq di SMP Negeri 2 Asembagus menjadikan siswa agar selalu mencintai kebenaran dalam setiap tindakan yang dilakukan.

\footnotetext{
18 Masnur Muslich, Pendidikan Karakter Menjawab Tantangan Multidimensional (Jakarta: Pt Bumi Aksara, 2011), hlm. 133.

19 Sofan Amri, Implementasi Pendidikan Karakter Dalam Pembelajaran (Analisis Dan Pengembangan Karakter Siswa Dalam Proses Pembelajaran) (Jakarta: PT Prestasi Pustaka Raya, 2011), hlm. 110.

20 Masnur Muslich, Pendidikan Karakter Menjawab Tantangan Multidimensional (Jakarta: Pt Bumi Aksara, 2011), hlm. 133.
}

288 JURNAL LISAN AL-HAL 
Pengetahuan moral dari Sistem Pembelajaran Pesantren dapat diwujudkan menjadi tindakan nyata Moral Action di SMP Negeri 2 Asembagus. Nilai-nilai karakter yang telah tertanam dalam diri siswa yang telah menjadi kebiasaan bagi siswa di SMP Negeri 2 Asembagus.

\section{Simpulan}

Berdasarkan penelitian yang dilakukan di SMP Negeri 2 Asembagus dalam penanaman nilai-nilai pendidikan karakter siswa dalam pendidikan pesantren diantaranya: Pertama, Penanaman Nilai-nilai Pendidikan Karakter di SMP Negeri 2 Asembagus. Nilai-nilai karakter yang ditanamkan kepada siswa di SMP Negeri 2 Asembagus, meliputi: a) Keimanan/ Religius, b) Kejujuran, c) Mandiri, d) Disiplin, e) Bersahabat/ Komunikatif, f) Rasa ingin tahu, g) Kerja keras, h) Demokrasi, i) Cinta Damai, j) Gemar membaca, k) Peduli lingkungan dan Menjaga kebersihan, l) Peduli Sosial, m) Semangat kebangsaan dan Cinta tanah air.

Kedua, Peran Sistem Pembelajaran Pesantren Dalam Penanaman Nilai-Nilai Pendidikan Karakter di SMP Negeri 2 Asembagus. Nilai karakter yang tertanam pada siswa di SMP Negeri 2 Asembagus diperoleh melalui pengajian kitab Taysirul Kholaq sebagai tahap pengajaran nilai-nilai karakter (Moral Knowing) dan pembiasan yang dilakukan oleh siswa (Moral Action) sehingga melahirkan pribadi siswa yang berkarakter positif (Moral Feeling).

\section{DAFTAR PUSTAKA}

Creswell, John, W. Research Design Pendekatan Kualitatif, Kuantitatif dan Mixed, Pustaka Pelajar, Yogyakarta, 2014.

Departemen Pendidikan Nasional, Kamus Besar Bahasa Indonesia, Pusat Bahasa Depdiknas, Jakarta, 2008.

Dhofier, Zamahsyari. Tradisi pesantren, Jakarta: LP3ES, 1984.

http://staff.uny.ac.id/sites/default/files/pendidikan/Drs.\%20Hiryanto,\% 20M.Si./belajar\%20dan\%20pembelajaran.pdf (pengertian pembelajaran, 11 Januari 2017, 10.00 a.m)

Institut Agama Islam Ibrahimy Sukorejo. Pedoman Penulisan Makalah, Proposal, dan Skripsi, Sukorejo: IAI Ibrahimy, 2017.

Kusuma, Dharma, dkk. Pendidikan Karakter (Kajian Teori Dan Praktik Di Sekolah) Cetakan ketiga, Bandung: PT Remaja Rosdakarya, 2012.

Mastuhu. Dinamika System Pendidikan Pesantren: Suatu Kajian Tentang Unsur Dan Nilai System Pendidikan Pesantren, Jakarta: INIS, 1994.

Mujamil, Qomar. Pesantren Dari Transformasi Metodologi Menuju Demokratisasi Institusi. Jakarta: Erlangga, 2005. 
Nasir, M. Ridlwan. Mencari Tipologi Format Pendidikan Ideal, Pondok Pesantren di Tengah Arus Perubahan. Yogyakarta: Pustaka Pelajar, 2005.

Nurhayati, Amin. Inovasi Kurikulum: Telaah Terhadap Pengembangan Kurikulum Pesantren. Yogyakarta: Teras, 2010.

Purwanti, "Implementasi Pendidikan Karakter Berbasis Pondok Pesantren Dalam Pembelajaran Pendidikan Agama Islam Di SMP Ali Maksum Yogyakarta", dalam

http://digilib.uinsuka.ac.id/11140/1/BAB\%25201,\%2520IV,\%2520

DAFTAR\%2520PUSTAKA.pdf\&sa=U\&ved=0ahUKEwjOvf3risvRAhXL rFQKHXMcAMggOMAA\&usg=AFQjCNGZcz2xBhDi5_X_2WRMtSi1RHz agA (10 Januari 2017, 20.00 p.m).

Purwati, Eni, dkk. Pendidikan Karakter (menjadi berkarakter muslimmuslimah indonesia), Kopertais IV Press, Surabaya, 2013.

Sugiyono. Metode Penelitian Kuantitatif, Kualitatif, dan $R \& D$, Alfabeta, Bandung, 2010.

Sukardi. Metodologi Penelitian Pendidikan, Kompetensi Dan Praktiknya, (Jakarta; Bumi Aksara, 2004, Cetakan Ke 2).

Sutama. Metode Penelitian Pendidikan Kuantitatif,Kualitatif, PTK, R\&D. Surakarta: Fairuz Media, 2012.

Syahid, Ahmad (Edt). Pesantren Dan Pengembangan Ekonomi Umat, DEPAG Dan INCIS, 2002.

Wahjoetimo. Perguruan Tinggi Pesantren Pendidikan Alternative Masa Depan. Jakarata: Gema Insani Press, 1997.

Zubaedi, Desain Pendidikan Karakter Konsepsi Dan Aplikasinya Dalam Lembaga Pendidikan (Jakarta: Kencana, 2011). 